\title{
CHRISTIAN FAITH VIEW ON MID-BRAIN ACTIVATION SYSTEM AND ITS IMPACT ON THE SPIRITUALITY OF CHILDREN AGED 6 TO 12 YEARS OLD IN SURABAYA
}

\author{
Connie Laurina \\ Evangelical Theological Seminary of Indonesia - Surabaya \\ E-mail: elzconn@gmail.com
}

\begin{abstract}
God created humans as the most special creation compared to His other creations. Human intelligence is caused by one organ which, although small in size, has a very vital role, namely the brain. Advances in knowledge and technology have encouraged scientists to try solving the mysteries of the brain. Many studies have focused on the right brain and left brain, or to balance the right brain and left brain. But in recent years, there has been a training/self-development institute who stated that they had found a way to balance the right and left brain, namely by activating the midbrain. This midbrain activation method is aimed at children aged 5-15 years because it is considered that children at this age are more easily activated in a very short time through a computer.The method used in writing this work is a Literature Study that contains various information on matters related to the topic of discussion. In addition to using literature, writing will be complemented by field research, using a Check List to interview respondents. The research approach used are qualitative and quantitative approach. A The qualitative approach obtains data regarding respondent's experiences. This writing has the aim of finding ( knowing ) whether the Midbrain Activation system is in accordance with God's Word or against God's Word; to open the horizons of parents, congregations and even readers of this paper, especially those with children, so that they can be more careful in choosing training for their children.
\end{abstract}

Keywords: intelligence, intellectual, Brain, Midbrain wave, Hypnosis, Children.

\section{INTRODUCTION}

The development of the world in various aspects of life results in significant changes in human life. Progress in various fields such as information technology, socio-culture, education, economy affects humans in terms of shifting patterns of human life and interactions between humans.
The challenge we face today is an intense competition in various fields. Therefore, humans are required to be more superior and have higher quality in life to face the competition and possibilities that may occur. Superior humans do not arise by themselves, it requires a long process to achieve. 
Since birth, children have been blessed with various genetic potentials. But the formation of attitudes, personality and development in children abilities are still influenced by environmental factors.

Therefore, many children's educational development begin at an early age. Parents play an important role in children's education and create an environment that allow their potential to grow optimal. Currently, there are many educational development institutions or training outside of formal schools, which are aimed at children. This is because children are an important asset and investment for life in the future, which not only benefits themselves but also for their parents, environment, church, society, nation, and state. Thus, educating children from an early age is the hope of parents so that these children grow into superior generations in the future, who are resistant to competition and challenges in the era of globalization.

Driven by the love and care of parents for their children, Without realizing it, many parents are competing to include their children in educational development/training institutions outside of formal schools. But here, sometimes parents don't have the right understanding about children's education. Because the selection of educational institutions that are not suitable for children will have impacts on their personality.

Recently there have been personal development/training institutes claiming they have found a scientific method that can train children to become genius/have basic abilities (think and act) beyond other children's ability in general.[1] This method trains the human brain by balancing the right brain and left brain by activating the midbrain.

Organizers of Midbrain Activation stated that the bridge to connect and balance the functions of the right brain and left brain is by "midbrain". Activation of the midbrain will restore brainpower to its original state. Midbrain activation was carried out for 2 days by using a computer and using audio.[2]

An indicator of active midbrain is that trainees with eyes closed can distinguish colors and images without going out of line, read written numbers and letters. Many parents are motivated to include their children in this midbrain training. This is due to stories from parents who have enrolled their children in this training institution and also the desire to make their children into geniuses. But as Christians, we need to look deeper into this Midbrain Activation method. 


\section{RESEARCH METHOD}

The method used in writing this work is a Literature Study that contains various information on matters related to the topic of discussion. In addition to using literature, writing will be complemented by field research, using a Check List to interview respondents. The research approach used are qualitative and quantitative approach. The qualitative approach obtains data regarding respondent's experiences, while the quantitative approach obtains data to be tested statiscally. Based on the existing theory, a hypothesis is formulated. The initial hypothesis used are:

1. Midbrain Activation affects children's spiritual behavior.

2. Midbrain activation affects children's daily behavior.

3. Activation of the Midbrain has an effect on certain personalities of children.

After the hypotheses are formulated, then the data are collected using a Check List for interviews before and after the children participated in the Midbrain activation. Data analysis will use statistical calculations/analysis. And from this analysis, conclusions will be drawn.

\section{RESULTS AND DISCUSSION}

\section{Middle Brain Activation System}

In recent years, training/self development institutions outside formal schools that use the method of activating children midbrain have emerged. This program is held to optimize the thinking ability, concentration, memory, creativity, and achievement of children so that in a relatively short time, the level of intelligence of children is expected to reach the level of genius.[9]

Initially the organizers of Midbrain Activation developed this activation method in Malaysia. The founder and inventor of this method is Tom Har, an expert trainer for NLP (Neuro Lingusitic Programming), a hypnotherapist, brain researcher and child development expert.[10] Midbrain Activation Organizer developed with a franchise system or franchise. Starting from Malaysia, the Central Brain Activation method entered Indonesia around 2009 and is now available in big cities throughout Indonesia.[11]

The activation organizer provides midbrain activation training for children aged 5-15 years which is carried out for 2 days. At the same time, training for parents is usually also carried out. This is because parents play a role in helping the children in developing their midbrain 
potential by practising everyday at home.

The abilities that children can do after activation are seeing cards with eyes closed (blind fold), being able to arrange playing cards by number, color and shape with eyes closed, being able to see patterns and colors complete with numbers only by using their sense of touch ( Skin Vision ). Another ability of these children can do is walk blindfolded, without crashing. An experiment was conducted on a child who walks with his eyes covered with a cloth. deliberately holding the road above. He can immediately dodge the obstacle without touching it. A child can even find inventions among other parents, without touching and hearing his voice.[12] At a more advanced level, a child is expected to be able to 'see' objects behind a wall or in a box.

He can even count the money in someone's wallet in front of him without the person taking out his wallet. If a child diligently trains his midbrain function, he can even read documents located in the closed position.[13] Organizers of Midbrain Activation stated that the method of activating the midbrain that they did was not something mystical or supernatural but was done in a scientific way. This midbrain activation uses a lot of Alpha brain waves. Alpha brain waves are scientifically proven to be brain waves that appear dominant when we are relaxed and most creative. [14] Children with activated midbrains emit brain waves that are similar to radar. This allows the owner to see objects with their eyes closed. The principle: what can be seen by the eye can also be seen by brain waves. Basically, the waves are located under the nose so the child is only able to detect objects that are located slightly below the nose. [15]



Figure 1

\section{Central Brain Wave 9}

However, regular practice can make children's abilities become stronger and able to see objects that are higher up. There are even some children who can detect up to 360 degrees. That means they can detect objects located behind, above and in all directions. 
Medical, Psychological, And Christian

Faith Review On Middle Brain Activation

Humans live in a world that is always changing. Various advances in many fields affect human life. These advances provide a better life for humans. But on the other hand, these advances also make people to always seek fast-paced solutions. Christian faith is always faced with every change or issue related to human life, including various progress. This is where the Christian faith plays a role to always give a good judgment objective in accordance with the foundation of God's Word. Midbrain activation training/selfdevelopment institute is one of the effects of technological advances.

Midbrain Activation is a training method by activating the midbrain of children aged 5-15 years by using computer technology. But right now this Midbrain Activation is facing the pros and cons among Christians.

\section{Medical Review of Midbrain Activation}

Central Brain Activation has been widely discussed in Indonesia several times this past year. Although many parents include their children in mid-brain training in order to make the children become smart and genius as stated by the organizers, but many neuroscientists claim that so far the midbrain activation method has not been proven scientifically medical and no harmful side effects. In the medical world, according to a neurologist who graduated from the Faculty of Medicine, University of Indonesia, Dr. Vivien Puspitasari, the midbrain has been known since the discovery of the anatomy of the nervous system.

The human brain is divided into three major parts based on its development from the fetus in the womb, namely the prosencephalon (for bra in), rhombencephalon (hind brain), and mesencephalon (midbrain). The midbrain is part of the brain which is located between the forebrain and hindbrain. The middle brain is composed of the nucleus of nerve cells and nerve fibers that have several special functions. This section like a channel or a passage flanked by the two halves of the brain.

But Dr. Vivien stated that until now in the medical field there is no strong scientific evidence supporting the effectiveness and impact of this method on the cognitive abilities child. Children's cognitive abilities, according to Dr. Vivien, not only determined activation midbrain. The ability to learn involves all components of the brain, fore brain with both hemispheres of the brain (right and left), cerebellum, and other components of 
the brain. Everything needs to be stimulated in a balanced and continuous manner. to produce optimal cognitive abilities and cannot be obtained in a short time. [3]

Many factors also determine a person's thinking ability, such as: heredity (genetics), family environment, place of residence, education, and gender received stimulation. Dr. Vivien also stated that with brain activation middle, if a person can distinguish colors, knows letters or numbers, reads with eyes closed or can make all limbs more sensitive, medically there is no scientific evidence and explanation. Furthermore, it is necessary to conduct further research to find out the effectiveness and usefulness of the midbrain activation method.

When viewed from the side of the potential intelligence of the brain in terms of practical neuroscience, there are seven parts of the brain that play a vital role in terms of intelligence, namely: the prefrontal area, the area of language and logic abilities, the art area, the area of creative ideas, the emotional (limbic) area, the memory consolidation (hippocampus), area cerebellum (cerebellum).

Prefrontal area (lower forebrain) anatomically, the prefrontal area is located in the lower forebrain, just behind the forehead. This part of the brain determines the ability to take initiative and consider something, whether a plan will be implemented or not, based on religious values, morals, customs noble values that become signs of action learned from childhood.[5]

This part of the brain is also important in terms of concentration and attention think. This part of the brain does not develop in animals, only in human only.

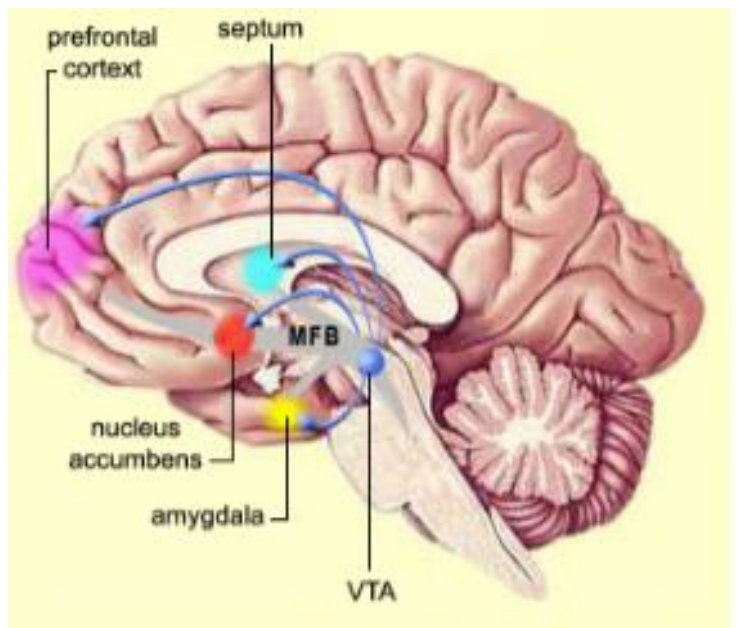

Figure 7: Prefrontal Brain Region (bottom forebrain)

Areas of language and logic abilities (left hemisphere). The left side of the brain is the brain associated with the arrangement of language structure and logical thinking activities as well as the center of mathematics. Part of This is a controller of the intelligence quotient (IQ) The memory of the brain part is also short-term. Art area involving feelings (right hemisphere)

The right hemisphere functions in the 
development of the Emotional Quotient (EQ). The right brain is related to communication, interaction with other humans, and emotional control. In this right brain also lies the ability intuitive and artistic. There is a connection between artistic feeling and creativity. Both of these are located in the same place, namely the right hemisphere of the brain.

Stimulation of the right brain properly will make the right brain develop and will strengthen another function, namely the function of creativity.

\section{Midbrain Activation Medical Study}

Based on the midbrain (mesencephalon) medically, The author found a discrepancy between the medical and the views of the organizers of midbrain activation.

(1). The organizer of the activation states that the midbrain is located in the middle of the right brain and left brain. And the midbrain is the bridge between the two hemispheres of the brain. One way to balance the right brain and left brain is to activate the midbrain so that the child will have extraordinary abilities and become a "genius" child. According to medical science, the midbrain (mesencephalon) is caused by the right brain and left brain. The right brain and left brain are opposed by the Corpus Callasum and not the midbrain.[7] The midbrain is located between the forebrain and hindbrain and connects the two.

(2). The function of the midbrain (mesencephalon) according to medical science is: as a pathway for electrical and chemical currents from the brain stem to the brain and large has nothing to do with the intelligence factor. The function of the brain related to intelligence is found in the big brain such as described above, where there are 7 potential areas of intelligence in the human brain and no mention is made of the midbrain region (mesencephalon) at all. Dwi Putro Widodo, Consultant Pediatric Neurologist RSCM Jakarta, mentions that the midbrain or the so-called midbrain is located at the base of the brain stem, also has a function to regulate eyeballs and not to make children intelligent instantly.[8]

(3). According to medical science, the midbrain (mesencephalon) does not need to be activated, because it is already active. As mentioned in the previous explanation, the function of the midbrain (mesencephalon) is also related to vision and hearing. If the midbrain is not active then the function of human vision and hearing will be disturbed. Neuroscientist Dr. Andreas Harry, SpS (K) from Gading Pluit Hospital states that the midbrain is the part of the brainstem that has functioned as the nucleus of eye movement and also in 
this area passes fibers that regulate breathing and consciousness.

This activity cannot be controlled or autonomous, so dr. Andreas questions which part of the midbrain can be activated to make children smart because the midbrain can't be controlled. Meanwhile, if what is meant by activating the midbrain is to activate the corpus callosum ( the bridge that connects the right and left brain ), it will lead to a question, how to activate it? More Dr. Andreas stated that to educate children is to how to train the left brain and right brain and not through the midbrain.[16] In medical science, every anatomical part of the brain has been mapped with the function of a PET-scan/fMRI study. Midbrain activation as mentioned by the organizers of the activation seems to neglect or even underestimate the function of other parts of the brain.

Thus the statement of the organizer of the activation about activating the midbrain is not medically acceptable. This raises the question that if it's not the midbrain that is activated, there must be an $\mathrm{X}$ factor behind it all. The organizer states that after the activation of the midbrain, the children will become "genius". However, according to the organizers, the definition of "genius" was not explained in detail. With the lure of "genius", not a few parents are tempted to register her son attending midbrain activation training. However, the ability to perform activities with their eyes closed is something that is beyond logic, but this lure actually increases the enthusiasm of parents to include their children. Intelligence/cognitive intelligence of the brain can be assessed based on scales that have been commonly used in the field of psychology, with standardized scales and parameters. An IQ test can be used to measure a person's intelligence ability in the fields of mathematics, linguistics, spatial, memory, reasoning, then given a certain value. The full assessment is as follows:

* Less than 70: mental retardation

70-80: the boundary between mental retardation and low $* 80-90$ : Low which is still in the normal category 90-110: normal or average 110-120: high in the normal category *120-130: superior 130 140: very superior * Above 140: genius.

A genius has an IQ of more than 140 . Genius does not match people who read with their eyes closed, read other people's minds, and so on. Children who have been activated should take clinical trials before and before activation, and then do an IQ test, to see if there is a change in their cognitive intelligence. 


\section{Overview of the Field of Psychology on} Midbrain Activation

Paul MacLean, a neuroscientist and Director of the Brain Behavior and Evolution Laboratory, the National Institute of Mental Health in America states that the human brain is divided into 3 major parts, namely: Neocortex Brain, Limbic Brain (limbic brain), Reptillian brain (brain stem). This theory is known as the name Triune Brain.[31]

1. Neocortex/Neomammalian brain, higher-order thinking: comprise two-thirds of the total mass of the brain and is the thinking brain. The brain consists of the left and right hemispheres of the brain.

2. Limbic Brain / Limbic Brain / Paleomammalian, consisting of midbrain surgery (midbrain) / Limbic System, emotions: is the part of the brain associated with emotions and instincts

\section{Reptillian Brain/ Reptillian Brain/} Protoreptillian/ Brain Stem is brain stem, survival. This brain controls muscles, balance, and autonomic functions such as breathing and heart rate.



Figure 13 : Triune Brain
The limbic system / midbrain operating system consists of:

*Amygdala, Hippocampus, Hippothalamus

*The midbrain operating system in addition to the 3 components above, also involves the brainstem, because the midbrain/mesencephalon is fused with the brainstem at the top, the mesencephalon includes in the limbic system/midbrain operating system.

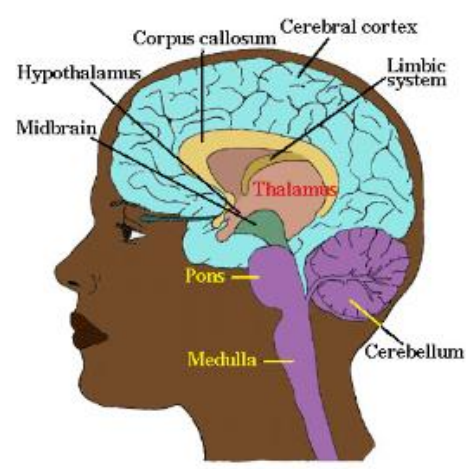

Gambar 14 : Sistem Limbik

The Neocortex brain operates the conscious mind.

The Limbic Brain / Limbic System acts as an intermediary between the conscious mind and the subconscious mind.

The Reptilian Brain / Brain Stem is involved in the operation of the subconscious mind.

\section{Brainwave Therapy}

The human brain produces certain dominant brain waves, which indicate brain activity at that time. Gamma and Beta waves represent the conscious mind. Alpha waves are between the conscious 
and subconscious mind/gateway to the subconscious.[34]

Theta and Delta waves represent the subconscious mind. A person is in a relaxed state and begins to be hypnotized, the dominant brain waves shift from beta to alpha (light trance / light trance). Trance is a condition in which the conscious mind is no longer in complete control and begins to be replaced by the subconscious mind. The deeper a person goes into a hypnotic state, the lower the brain waves, starting to enter theta (medium trance) and delta (high trance).[35]

Research shows that brain waves not only indicate the state of a person's mind and body but can also be stimulated to change a person's mental state. By conditioning the brain to produce or reduce certain types of brain wave frequencies, it is possible to produce a variety of mental and emotional states. Brainwave stimulation is also known as Brainwave Therapy. Brainwave Therapy was first discovered by German scientists named Heinrich Wilhelm Dove in 1839. Brain wave therapy can be done with Binaural Beat Frequency and Isochronic Entrainment techniques. Benaural Beat Frequency technique refers to the resonance system, which is the process of joining the vibration of one object against another with the same frequency. This technology is guided by the principle that there is a beat produced by 2 sounds with different frequencies, with a mathematical formula: $\mathrm{F}$ beat $=\mathrm{f} 1-\mathrm{f} 2$.

Benaural Beat Frequency application is to use a brainwave $\mathrm{CD} /$ cassette containing music accompanied by a buzzing sound, which emits waves with a certain frequency that is conditioned according to the desired brain waves. This brainwave music is played through stereo headphones. As we know, the hypnotic state is achieved when the brain wave pattern is in alpha $(8-12 \mathrm{~Hz})$ or theta $(4-8$ $\mathrm{Hz}$ ), then 2 different sound waves, so the human brain experiences resonance due to the difference in brain waves. For example, if you want to achieve the wave pattern theta brain with a frequency of $6 \mathrm{~Hz}$, then a different frequency is made between stereo music on the right and left, for example, $300 \mathrm{~Hz}$ is made on the right and $306 \mathrm{~Hz}$ on the left. Thus, the difference in waves (F beat) of $6 \mathrm{~Hz}$ will be generated which is used to stimulate the brain. Isochronic Entrainment works the same way as Benaural Beat. It's just that Benaural Beats uses headphones (left and right), while Isochronic Entrainment uses very loud audio.[36] This technology can also cause side effects because it can trigger stress, evoke memories of past suffering, sleep problems, addiction, and so on.[37] 


\section{Data collection technique}

In this study, the data collection technique was carried out by interview (interview), observation (observation), and Check List. The author conducted interviews with several parents and children who have participated in the activation, as well as several teachers. The purpose of the interview is to obtain data in the form of an experience story about the process of activation of the midbrain followed by the child, to find out if there are any disturbances or problems arise after following the activation, to find out the state and changes of the children before following the activation of the midbrain and after following the activation of the midbrain.

The Author has undergone observation to see the respondent's activities. There is this child which in this case his midbrain has been activated. The child did a demonstration of reading with blind fold. The author also attended midbrain activation training in one of the midbrain activation agencies in the East Surabaya area, at the stage/briefing session for parents and a demonstration of children who have been activated.

The author completes the study with a Check List to see whether there is an influence between midbrain activation on children's spiritual behavior, children's daily behavior, and children's personality. To obtain the data that the author expects, so in this study used to fill out the Checklist before the child participates in midbrain activation and after the child participates in midbrain activation. Check List Likert scale that uses five numbers, namely: (1) not at all, (2) less, (3) enough, (4) good, (5) very good.

\section{Data Presentation and Analysis}

in this study, the variables to be analized in hypoyhesis testing are :

- The independent variable ( which affect ) is Midbrain activation.

- The dependent variables ( influenced variables ) are : spiritual behaviour, daily behaviour, and personality. The initial hypothesis used is:

1. Ho = Midbrain Activation has NO effect on Spiritual Behavior

$\mathrm{H} 1$ = Midbrain Activation has an effect on Spiritual Behavior

2. $\mathrm{Ho}=$ Midbrain Activation has NO effect on Daily Behavior

$\mathrm{H} 1=$ Midbrain Activation has an effect on Daily Behavior

3. $\mathrm{Ho}=$ Midbrain Activation has NO effect on Personal

$\mathrm{H} 1=$ Midbrain Activation has an effect on Personal, Significancy level is $5 \%$, so: conditions to accept Ho is the 
significancy of the result count $>0.05$. The condition for rejecting $\mathrm{Ho}$ is the significancy of the result count $<0.05$.

\section{Statistical Analysis Results}

The Effect of Midbrain Activation on Spiritual Behavior

The author's purpose of conducting a check list of children is to determine whether there is an effect of midbrain activation on children's spiritual behavior before and after following the activation. The spiritual behaviors are the ability to memorize verses of God's word, the enthusiasm when praising God and listening to God's words, the ability to understand word of God, and lastly is the behaviour that loves to pray. The results of data processing using SPSS version 16.00 are as follows:

From the Paired Samples Correlations table, it can be seen that the results Data processing showed a correlation between midbrain activation and spiritual behavior of 0.646 , where the correlation level showed a substantial level of relationship. The level of this relationship is quite high. (According to Young, the high correlation value is 0.40 to $0.70)$.

\section{Paired Samples Test}

Based on the Paired Samples Test table, the comparison before and after activation, the significancy result is $0.006>0.05$, meaning that $\mathrm{Ho}$ is rejected, and $\mathrm{H} 1$ is accepted. This means that midbrain activation has an effect on spiritual behavior.

\begin{tabular}{|cc|c|c|}
\hline & $\begin{array}{c}\text { Behavior } \\
\text { Spirituality } \\
\text { Before }\end{array}$ & $\begin{array}{c}\text { Behavior } \\
\text { Spirituality } \\
\text { After }\end{array}$ \\
\hline $\mathrm{N}$ & Valid & 33 & 33 \\
\hline & Missing & 0 & 0 \\
\hline Mean & 15.03 & 13.12 \\
\hline
\end{tabular}

The results of data analysis and spiritual behavior diagrams before activation and after activation show a change in spiritual behavior before and after activation, in the direction of decreasing. The author found that approximately $30 \%$ of children experienced a decline in their memorization of memorizing verses and enthusiasm for listening to God's Word. This is because children lack concentration and are lazy to concentrate when studying God's Word.

There was also a decrease in children's behavior as much as $21 \%$ in terms of the spirit of praising God during praise and worship events at Sunday schools. There are even certain children who do not want to go to Sunday school, 
children prefer to practice blindfold reading. The most is a decrease in terms of prayer, which is about $50 \%$ of children. Average children that the author found was they prayed only during the Sunday school, they rarely or even did not have prayers hours at home.

There were children who previously still prayed before eating, after activation they didn't even pray at all/ were lazy to pray. The decline in spiritual behavior must also be taken into consideration because spiritual teaching to children affects the spiritual quality of children to adulthood. According to Meir: The more appropriate the spiritual education given to children, the more children will hold fast to the Christian faith as adults and accept Jesus Christ as Savior.

\section{The Effect of Midbrain Activation on Personality}

The author's aim was to see if there was an effect of midbrain activation on the children's personality before and after following the activation, in terms of arrogance, aggressiveness / like to annoy friends (such as mocking, hitting, and bullying). etc.), and honesty. The results of data processing using SPSS version 16.00 are as follows:

From the Paired Samples Correlations table, the results of data processing show a correlation between midbrain activation and spiritual behavior of 0.64 , this indicates a substantial level of relationship (According to Young, the value of a substantial correlation/relationship is 0.40 to 0.70$)$.

\section{Paired Samples Test}

Based on the Paired Samples Test table, comparison before and after activation, the significancy result is $0.348>0.05$, so Ho is accepted. However, the Paired Samples Correlations table shows that there is a correlation/relationship between activation and certain personalities of children (in terms of arrogance, aggressiveness, honesty).

So it can be concluded that from the results of the research that the author did regarding midbrain activation at this time there is still NO influence on the child's personality (in terms of arrogance, aggressiveness, honesty), but for the longterm impact of the effect of activation on the child's personality (in terms of arrogance, aggressiveness, honesty) persist. This is due to research that The author is limited by time. Meanwhile, children are still experiencing a phase of "growth and development" both physically and psychologically and in terms of their personalities.

However, from the table Paired Samples Correlations, the author obtained 
data that there is a relationship between activation and certain personalities of children. Because it's needed further research on the above.

\begin{tabular}{|l|c|c|}
\hline & $\begin{array}{c}\text { Personality } \\
\text { Before }\end{array}$ & $\begin{array}{c}\text { Personality } \\
\text { After }\end{array}$ \\
\hline N Valid & 33 & 33 \\
\hline Missing & 0 & 0 \\
\hline Mean & 7.03 & 7.30 \\
\hline
\end{tabular}

Results of data analysis and diagrams of certain personal behaviors (in terms of arrogance, aggressiveness, and honesty) before activation and before activation showed any changes, although only small. The authors found $27 \%$ respondents experienced an increase in arrogance. After participating in the activation, these children like to show off their abilities/like to show off, feel smarter than others, feel more capable so they don't want to learn. In terms of aggressiveness, the author found $10 \%$ of these children to be children who like to mock, annoy friends/siblings, to cheat. In terms of honesty, the author finds almost no influence between before and after activation, the author found $6 \%$ of respondents who used their abilities to be dishonest during tests/cheats.

Although the data obtained regarding changes in children's arrogance, aggressiveness, and honesty are not very significant, they must still be considered. Because children naturally don't have abilities such as blindfold reading. Children who are not ready with their suddenly acquired "ability" will definitely affect their personality, so that children become arrogant, aggressive, and so on. In fact, it is not impossible that children can abuse their "ability" for useless things and even harm others.

\section{CONCLUSION}

Based on literature and field studies accompanied by data collection, data processing, and analysis, then in the end the author can conclude as follows:

1. Midbrain Activation influences certain spiritual behaviors in children. This can be seen from the changes before participating in the Activation and after participating in the Activation, there was a decrease in some children in terms of memorizing God's Word, enthusiasm in listening to God's Word. The longing and enthusiasm for praising God and praying were also found to be decreased in some children. Although the percentage change is not too big, it still shows a decrease.

2. In terms of spirituality, the author also encountered a special case during the field study, namely: The existence of a child who experienced trauma and sleeps disorders they are blind fol of seeing the 
sun continuously in his head even though he had closed his eyes. There are children who cannot read the Bible when. The writing on the Bible looks like a blank sheet. There are children who cannot read the Bible when they are blindfolded and scream when told to read the Bible. This child was finally prayed for deliverance.

3. The author sees that Midbrain Activation can also make children have supernatural abilities but does not make children become geniuses. This can be seen from several examples, including can see writing from a distance of $6 \mathrm{~m}$ with the eyes closed and the lights in the room off can read the numbers on the Identity Card (KTP) with eyes closed, can read the numbers and colors on the card, can read newspapers with eyes closed can play computer games with eyes closed can cycle with eyes closed. The abilities above is the ability of ESP (Extra Sensory Perception). This shows that Midbrain Activation is an attempt to activate the soul power of the child and ESP itself is the entrance to the Occult.

4. Midbrain activation has an influence on children's psyche, including a number of certain children who are traumatized, shouting to get out at the time of activation (at the stage of Brain Wave Therapy). There are several children who are traumatized and have sleep disturbances due to fear of the dark, fear and remember sounds at the time of activation ( at the stage of Brain Wave Therapy ). There is a tendency to be proud because they have more abilities than their peers. This can be seen in the attitude of children who want to show off their abilities. In the early stages, children only want to show their strengths, but there is still a possibility that this pride will turn into arrogance and self-reliance. There is a desire to abuse his abilities in a negative direction, in this case, what the author encounters is to use his mind/concentrate on cheating during the test. There is a tendency to deceive parents in children who fail to do Blind Fold Reading by peeking from behind the blindfold to cover their failure.

5. The author sees a change in terms of obedience. There are some who claim that children become more obedient after activation. However, obedience to parents is actually related to the values that parents teach to children. If there is an increase in obedience after activation, what is likely to happen is: there is "programming" of nature children's subconscious that causes children to obey their parents, for example by hugging, and so on. However, if the effect of hypnosis is lost, the child will return to his original behavior.

6. The author concludes from interviews with parents that in some 
children, concentration, memory, and memorization increase in the early postactivation stage but after a few months, the child's behavior returns to normal.

7. The author sees that there are children who succeed and there are children who do not succeed in seeing with their eyes closed (Blind Fold Reading).

8. Based on data in the field as well as theories from various literature, the author concludes that Midbrain Activation is contrary to God's Word and is dangerous to do on children aged 6-12 years. This can be seen by looking at the impact of certain disorders or traumas on some children. Matthew 7:16-17 states: "By their fruit, you will know them. .......Thus every good tree bears good fruit, while a bad tree produces bad fruit."

9. The author concludes that this Midbrain Activation shows a scientific guise of heresy and is indirectly related to the Occult and the New Age Movement. Erwin W. Luitzer and John F. deVries stated one of the strategies of the New Age Movement, among others: "Sell your product under the guise of science...the only strategy master has to have is the right sales approach. Occult practices are advertised as "scientific"......Magic is denied; pseudo science is accepted. As long as there is an explanation, a lot of people think it must really be so. 1 This can be seen in Midbrain Activation which uses the term "midbrain" and states that the method they use is scientific because it uses a computer device, and there is nothing mystical, magic, and so on. While medically, the author found that although the "midbrain" (mesencephalon) does exist, its function is not as stated by the organizers of Midbrain Activation. The function of the midbrain (mesencephalon) is not related to intelligence factors. The term "midbrain" is just a cover to make it look scientific.

10. In the field of Psychology, the author found that Midbrain Activation is disguised hypnosis. This can be seen from the existence of Brain Wave Therapy which is carried out on children which actually aims to enter the child's subconscious mind. The children were led to enter the Alpha-Theta state which is the area of hypnosis.

11. The author finds the characteristics of Midbrain Activation which are the same as those found in the New Age Movement, namely: The presence of the sun element as in yoga, meditation, kundalini, and other mysticism. In midbrain activation, children are also invited to imagine and include the sun in their brains. Children have instilled in them a view that in them there is potential and strength, thinking beyond limits, anything is possible. The New Age 
Movement uses a lot of alpha-theta waves therapy methods, and the same method is used by Midbrain Activation organizers aimed at children. Jonathan D James states: Hypnosis, self-suggestion, ….are development processes in the New Age. Emphasis on self-control (mind control ) can be seen in various programs such as ......Alpha Training Level.... [15]

12. Midbrain Activation provides training to children aged 5-15 years. Age 6-12 years is the active period of children, whereas the first 10 years is a period in which children absorb a large amount of information obtained at that time. While the age of 12-15 years is the age of change for children, where children are in a critical period and experiencing a transition from childhood to adulthood. This needs to be considered because children are the future of the family and church.

13. The author realizes that time constraints also affect the results of observations in the field, therefore the author hopes that there will be further research on this Midbrain Activation.

\section{REFERENCES}

[1] Afifi, John. The Secret Behind the Power of the Midbrain. Surabaya: Dee Publishing, 2010.

[2] Andhika, Rini. Superbrain: Midbrain Activation. Jakarta: Popular Puspa, 2010.
[3] Andrews, Dr. Synthia. The Path of Energy. USA: The Career Press Inc., 2011. [4] Basrowi, M.Pd. and Dr. Suwandi, M.Si. Understanding Qualitative Research. Jakarta: PT Rineka Cipta, 2008.

[5] Bear, Mark F. and friends. Neuroscience Exploring The Brain. Philadelphia: Lippincott Williams \&amp; Wilkins, 2007.

[6] Beck, Joan. How to Raise A Brighter Child. New York: Pocket Books, 1999.

Berkhof, Louis. Systematic Theology of the Doctrine of God. Surabaya: Momentum Publisher, 2004.

[7] Berkhof, Louis. Systematic Theology of the Doctrine of Salvation. Surabaya: Publisher Momentum, 2004.

[8] Brill, J. Wesley. Solid Foundation. Bandung: Kalam Hidup Foundation, 1999. Bittlinger, Arnold. Archetypal Chakras. Canada: Weiser Books, 2001.

[9] Brown, Rebecca, MD. Prepare for the War of the End Times. Light Publishing, 2007 .

[10] Brown, Rebecca, MD. Become a Vessel of Glory. Yogyakarta : Andi Publisher, 2008.

[11] Carlson, Neil R. Physiology of Behavior. Boston: Pearson, 2010.

[12] Claproth, Richard, Ph.D. The Great Danger of Midbrain Activation. Jakarta: PT Gramedia, 2010.

[13] Co., Stephen and Eric B. Robins, 
M.D. Your Hands Can Heal You. USA:

Free Press, 2002.

[14] Cousens, Gabriel, M.D. Spiritual Nutrition. USA : North Atlantic Books

Dandelek, J. Allen. The Case For Reincarnation. USA : Llewwllyn Publication, 2010.

[15] Deidre, Martin and Bobgan. Hypnosis: Medical, Scientific, or Occultic? California: East Gate Publishers, 2001.

[16] DeLong, Douglas. Ancient Teaching. USA: Llewllyn Publications, 2005.

[17] Doherty, Sam. Why Evangelize Children. Jakarta: Indonesian Children's Evangelization Institute, 2000.

[18] Doherty, Sam. Obedience of Heavenly

Vision. Jakarta: Indonesian Children's Evangelization Institute, 2000.

[19] Elmore, Dr. Team. Developing Leadership Talents in Your Child. Jakarta: Immanuel Evangelical Foundation, 2002. [20] Enns, Paul. The Moody Handbook of Theology. Malang: SAAT Literature, 2004.

[21] Farrant, Thomas Ashley. Mantra Chakras. Canada : Red Wheel, 2006.

[22] Ferguson, Duncan Sheldon and John A. Sanford. New Age Spirituality : An Assessment. USA: Westminster/ John Knox Press, 1993.

[23] Fitzgerald, M.J. Turlough and friends. Clinical Neuroanatomy And Neuroscience. Philadelphia: ElSevier Saunders, 2007.
[24] Gardner, Howard. Multiple Intelligences. United States of America: Basic Books, 1993.

[25] Goldberg, Dr. Bruce. New Age Hypnosis. USA: Llewllyn Publication, 1998.

[26] Groothuis, Douglas R.. Unmasking the New Age Movement. Surabaya: Momentum Publishers, 2008.

[27] Gunawan, Adi W. Hypnotherapy The Art of Subconscious Restructuring. Jakarta: PT Gramedia, 2009.

[28] Gunarsa, Singgih D. \&amp; Dra. Yulia Singgih D. Gunarsa. Child Development Psychology \&amp; Teenager. Jakarta: BPK Gunung Mulia, 2002.

[29] Guiley, Rosemary Ellen. Encyclopedia of The Strange Mystical \&amp; Unexplained. USA : Visionary Living Inc., 1991.

[30] Hadisubrata, Drs. M.S., M.A.. Improving the Intelligence of Toddlers. Jakarta: BPK Gunung Mulia, 1994.

[31] LeDoux Joseph . The Emotional Brain, Yogyakarta: Pustaka Baca, 2010 [32]http://www.wisdompage.com/roleofval ues.html , accessed March 11, 2011 [33]http://departments.weber.edu/chfam/25 70/Neurology.html , accessed 11 March 2011

[34] Dr. Ir. H. Widiasmadi Nugroho, M.Eng. Super Brain, Jakarta: Kawahmedia, 
Theological Journal Kerugma

E-ISSN: 2622-1039

P-ISSN: 2621-8038

2010

[35] Saraswati. Hypnosis For Intelligence and Healing. Yogyakarta: Exciting Books, 2010

[36] Susan Grace H. Widiono, S.MG.

Seminar. "The Genius of the Bible Way" , Jakarta, 2010,

[37] Richard Claproth, PhD. The Great Danger of Central Brain Activation , Jakarta: PT Gramedia, 2010 